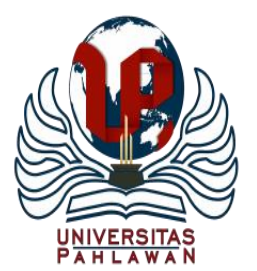

Jurnal Basicedu Volume 5 Nomor 1 Tahun 2021 Halaman 334-342

JURNAL BASICEDU

Research \& Learning in Elementary Education

https://jbasic.org/index.php/basicedu

\title{
Pengembangan Desain Pembelajaran Model Assure Berbasis Problem Based Learning Menggunakan Komik di Sekolah Dasar
}

\author{
Neneng Darlis ${ }^{1}$, Farida.F ${ }^{2}$, Yalvema Miaz $^{3}$ \\ Pascasarjana, Fakultas Ilmu Pendidikan, Universitas Negeri Padang, Indonesia ${ }^{1}$ \\ Fakultas Ilmu Pendidikan, Universitas Negeri Padang, Indonesia ${ }^{2,3}$ \\ E-mail : darlisneneng85@gmail.com ${ }^{1} \underline{\text { faridafachruddin67@ gmail.com }}^{2}$ yalmiaz@gmail.com ${ }^{3}$
}

\begin{abstract}
Abstrak
Penelitian ini bertujuan menghasilkan desain pembelajaran model ASSURE yang valid, praktis, dan efektif pada pembelajaran tematik terpadu tema 8 kelas V Sekolah Dasar. Desain pembelajaran yang dikembangkan adalah dalam bentuk Rencana Pelaksanaan Pembelajaran (RPP). Jenis penelitian ini menggunakan penelitian pengembangan dengan model ASSURE. Subjek penelitian ini adalah peserta didik kelas V UPTD SDN 02 Simpang Kapuak. Data dikumpulkan menggunakan lembar pengamatan keterlaksanaan desain pembelajaran, angket respon peserta didik, angket respon pendidik, lembar pengamat anak aktivitas siswa selama proses pembelajaran dan hasil belajar. Data yang diperoleh diolah dan dianalisis secara deskriptif. Diharapkan hasil penelitian desain pembelajaran yang dikembangkan menunjukkan kategori sangat valid. Berdasarkan hasil uji coba, diperoleh hasil bahwa desain pembelajaran memenuhi aspek kepraktisan ditinjau dari respon pendidik dan peserta didik. Desain pembelajaran juga memenuhi aspek keefektifan dilihat dari: 1) aktivitas peserta didik; 2) sikap peserta didik; 3) pengetahuan peserta didik yang melampaui KKM; dan 4) keterampilan peserta didik. Desain pembelajaran (RPP) yang dikembangkan memiliki karakteristik: 1) praktis dalam penggunaan, 2) penggunaan bahasanya jelas, logis, dan sistematis.
\end{abstract}

Kata kunci: desain pembelajaran, model ASSURE, pembelajaran tematik terpadu

Abstract

This study aims to produce ASSURE model that is valid, practical, and effective of learning design on integrated thematic learning theme 8 grade $V$ Elementary School. Learning design developed is in the form of Learning Implementation Plan (RPP). This type of research uses development research with the ASSURE model.The subjects of this study were students of class V UPTD SDN 02 Simpang Kapuak. Data were collected using observation sheets for the implementation of the learning design, student response questionnaires, teacher response questionnaires, observation sheets of student activities during the learning process and learning outcomes.The data obtained were processed and analyzed descriptively. It is expected that the results of the developed learning design research show very valid categories. Based on the trial results, it was found that the learning design fulfilled the practical aspect in terms of the responses of educators and students. The learning design also fulfills the aspect of effectiveness seen from: 1) student activities; 2) the attitude of students; 3) learners' knowledge that goes beyond the KKM; and 4) the skills of students.The learning design (RPP) developed has the following characteristics: 1) practical in use, 2) the use of language is clear, logical, and systematic.

Keywords: learning design, ASSURE model, integrated thematic learning

Copyright (c) 2021 Neneng Darlis, Farida. F, Yalvema Miaz

$\triangle$ Corresponding author

Address : Kec. Mungka, Kabupaten Lima Puluh Kota

Email : darlisneneng85@gmail.com

ISSN 2580-3735 (Media Cetak)

DOI: https://doi.org/10.31004/basicedu.v5i1.689

ISSN 2580-1147 (Media Online) 
335 Pengembangan Desain Pembelajaran Model Assure Berbasis Problem Based Learning Menggunakan Komik di Sekolah Dasar - Neneng Darlis, Farida. F, Yalvema Miaz

DOI: https://doi.org/10.31004/basicedu.v5i1.689

\section{PENDAHULUAN}

Pendidikan merupakan hal penting bagi kehidupan manusia yang dapat menentukan tingkat kemajuan suatu bangsa. Manusia tidak dapat berhenti belajar karena setiap permasalahan yang dihadapi manusia dalam hidupnya membutuhkan pemecahan dan menuntut manusia untuk belajar menghadapinya.

Pelaksanaan pendidikan di Indonesia secara garis besar diatur oleh Kementerian Pendidikan dan Kebudayaan Republik Indonesia melalui penetapan Standar Nasional Pendidikan (SNP). SNP dijabarkan ke dalam 8 standar yang memuat kompetensi tertentu yang harus dikuasai siswa pada jenjang pendidikan tertentu. Pelaksanaan pendidikan diatur melalui penetapan kurikulum.

Sejak zaman kemerdekaan sampai sekarang, kurikulum pendidikan di Indonesia sudah mengalami 11 kali perubahan kurikulum dalam dunia pendidikan Indonesia. Sejak tahun 2015 di Indonesia diberlakukan Kurikulum 2013 yang secara bertahap dilakukan di semua jenjang pendidikan.

Perubahan kurikulum seyogyanya direncanakan secara matang. Menurut Krissandi \& Rusmawan (2015) dalam perencanaan tersebut diperlukan evaluasi menyeluruh terhadap kurikulum lama, analisis kebutuhan tantangan zaman, penyusunan perangkat kurikulum, dan sosialisasi secara optimal.

Arah kebijakan pada pelaksanaan Kurikulum 2013 saat ini adalah dengan program "Merdeka Belajar" yang harus dilaksanakan selama proses pembelajaran. Dengan demikian proses pembelajaran harus dilaksanakan dengan menyenangkan dan boleh dilakukan di mana saja. Salah satu tempat belajar yang paling dekat dengan siswa adalah lingkungan.

IPA merupakan satu muatan mata pelajaran yang ada pada kurikulum sekolah dasar (SD) yang mengkaji lingkungan alam serta gejala-gejalanya dalam kehidupan sehari-hari. Dalam pelaksanaan kurikulum 2013, proses pembelajaran dilaksanakan secara tematik terpadu. Pembelajaran tematik terpadu merupakan pembelajaran dengan mengintegrasikan beberapa muatan pelajaran ke dalam suatu tema. Pelaksanaan pembelajaran tematik terpadu berpusat pada siswa, tidak tampaknya pemisah antar mata pelajaran, konsep disajikan dari berbagai mata pelajaran, fleksibel, hasil pembelajaran berkembang sesuai dengan kebutuhan dan minat siswa. Kemendikbud (2016) menjelaskan bahwa konsep pendekatan ilmiah (scientific approach) dalam pembelajaran mencakup kegiatan mengamati, menanya, mencoba, mengolah, menyajikan, menyimpulkan, dan mencipta.

Pembelajaran tematik terpadu yang dilaksanakan di SD seharusnya mampu mengembangkan kemampuan berpikir siswa dalam melakukan suatu penemuan sehingga menghasilkan siswa yang mampu berpikir kreatif dan kritis terhadap permasalahan yang ada di sekitarnya. Untuk mengembangkan kemampuan berpikir tersebut pembelajaran hendaklah berorientasi kepada masalah dalam kehidupan sehari-hari. Salah satu model pembelajaran yang berorientasi kepada masalah dan mampu mengembangkan kemampuan berpikir siswa 
336 Pengembangan Desain Pembelajaran Model Assure Berbasis Problem Based Learning Menggunakan Komik di Sekolah Dasar - Neneng Darlis, Farida. F, Yalvema Miaz

DOI: https://doi.org/10.31004/basicedu.v5i1.689

adalah model pembelajaran Problem Based Learning (PBL).

Kusnandar (2013) menyatakan bahwa Model Problem Based Learning adalah model pembelajaran yang menggunakan masalah dunia nyata sebagai konteks bagi siswa untuk belajar berpikir kritis dan keterampilan pemecahan masalah, serta untuk memperoleh konsep esensial dan pengetahuan dari materi pelajaran.

Pembelajaran dengan PBL dapat menciptakan pembelajaran yang berpusat kepada siswa (students centered) yang mengutamakan proses dalam pembelajarannya. Hal ini sejalan dengan salah satu karakteristik pembelajaran tematik terpadu yaitu berpusat pada siswa.

Pembelajaran tematik terpadu tidak lepas dari media dan bahan ajar yang digunakan. Media dan bahan ajar yang umum dan sering digunakan di sekolah adalah berupa buku teks atau modul dengan ciri khas banyak tulisan atau penjelasan dan sedikit gambar yang cenderung membuat siswa bosan dan kurang termotivasi.

Daryanto\& Tasrial (2012) mengemukakan bahwa siswa cenderung tidak menyukai buku teks apalagi tidak disertai gambar atau ilustrasi yang menarik, dan secara empirik siswa cenderung menyukai buku bergambar, penuh warna, dan divisualisasikan dalam bentuk realistis atau kartun.

Banyak asumsi menyatakan bahwa pembelajaran tematik terpadu merupakan pelajaran yang padat materi, sulit dan dengan penggunaan media dan metode yang kurang inovatif, maka akan mengakibatkan siswa malas belajar dan minatnya berkurang. Minat merupakan modal awal terbentuknya motivasi. Arigiyati mengemukakan bahwa jika seseorang memiliki motivasi besar, maka ia akan menampakkan minat, perhatian, konsentrasi, ketekunan, serta orientasi akan prestasi tanpa mengenal rasa bosan, jenuh, dan menyerah.

Ciri khas siswa usia belajar jenjang SD adalah lebih tertarik pada bacaan ringan dan menyenangkan. Mereka lebih banyak meluangkan waktu untuk membaca komik dibandingkan buku pelajaran. Sebab menurut mereka, membaca komik tidak membutuhkan pola pikir yangerat.

Charlina et al. (2020) mengemukakan bahwa komik merupakan media yang sangat dekat dengan anak-anak selain televisi. Hal ini didukung dengan hasil survei AC Nielsen terhadap audience usia 5-14 tahun, tanggal 29 April-26 Mei 2007 di lima kota besar di Indonesia. Berangkat dari hal tersebut, komik bisa dijadikan "pintu masuk" untuk menumbuhkan minat baca terhadap buku pelajaran.

Sejalan dengan hal di atas, hasil penelitian Puspitorini et al. (2014), penggunaan media komik dalam pembelajaran IPA mampu meningkatkan; (1) motivasi belajar siswa sebesar 0,55 (sedang), (2) hasil belajar siswa ranah kognitif sebesar 0,42 (sedang), dan, (3) hasil belajar siswa ranah afektif sebesar 0,34 (sedang).

Melalui komik, informasi yang akan disampaikan dapat tersampaikan secara efektif. Kombinasi gambar, tulisan dan alur cerita yang jelas dapat meningkatkan daya imajinasi siswa serta daya kembang logika yang dikolaborasikan dengan pengalaman serta masalah yang ditemukan sehari-hari. Terkait dengan model pelaksanaan pembelajaran, maka harus direncanakan atau 
337 Pengembangan Desain Pembelajaran Model Assure Berbasis Problem Based Learning Menggunakan Komik di Sekolah Dasar - Neneng Darlis, Farida. F, Yalvema Miaz

DOI: https://doi.org/10.31004/basicedu.v5i1.689

didesain dengan matang. Berbagai jenis desain pembelajaran berkembang saat ini. Salah satu desain tersebut adalah desain pembelajaran model ASSURE.

Desain pembelajaran ASSURE merupakan petunjuk prosedural dalam merencanakan dan menjalankan pembelajaran termasuk media dan teknologi pembelajaran yang akan dipakai. Model ASSURE merujuk pada analisis kebutuhan ideal untuk suatu kegiatan pembelajaran yang hasilnya diyakini dapat membantu guru mencapai tujuan pembelajaran secara efektif dan efisien. Karena seluruh aktifitas pembelajaran yang diterapkan merupakan hasil analisis yang mendalam yang dituangkan dalam suatu perencanaan yang resmi dan selanjutnya diaplikasikan dalam kegiatan pembelajaran (Pribadi:2010).

Bajracharya (2019) menyatakan bahwa, desain pembelajaran adalah "the systemic and reflective process of translating principles of learning and instruction into plans for instructional materials, activities, information resources, and evaluation". Dalam hal ini, Smith dan Ragan's menegaskan bahwa desain pembelajaran adalah proses yang sistematis dan reflektif dalam menerjemahkan prinsip dan langkah pembelajaran kedalam perencanaan bahan ajar, aktifitas, sumber, dan evaluasi pembelajaran.

Desain pembelajaran sebagai proses merupakan pengembangan pembelajaran secara sistematik dan menggunakan teori pembelajaran secara khusus untuk menjamin kualitas pembelajaran (Sagala, 2012).

Desain pembelajaran model ASSURE dikembangkan oleh Smaldino, dkk, tahun 2005.
Huruf demi huruf dari kata-katanya merupakan rincian langkah-langkah dalam membuat rancangan pembelajaran. Desain pembelajaran model ASSURE adalah suatu rencana yang digunakan untuk membantu guru mengorganisasikan prosedur pembelajaran, dan melakukan penilaian autentik (Baharun, 2016).

\section{METODE}

Penelitian ini dilaksanakan di UPTD SDN02 Simpang Kapuak. Subjek penelitian adalah siswa kelas V UPTD SDN 02 Simpang Kapuak tahun pelajaran 2019/2020. Penelitian pengembangan yang dilakukan menggunakan model pengembangan ASSURE berbasis PBL.

Terdapat enam tahapan yang harus dilalui dalam model ASSURE yaitu: (a) menganalisis siswa (analyze learner), (b) merumuskan standar dan tujuan (state standard and objectives), (c) memilih strategi, teknologi, media dan materi ajar (select methods, media, and materials), memanfaatkan teknologi, media dan materi ajar (utilize methods, media, and materials), (e) mengajak siswa untuk berpartisipasi (requires learner participation), (f) melakukan evaluasi dan revisi (evaluate and revise). Jenis data yang akan diambil pada penelitian ini adalah data deskriptif, yaitu mendeskripsikan pengembangan desain pembelajaran, tingkat validitas, praktikalitas, dan efektifitas desain pembelajaran.

Teknik pengembangan desain pembelajaran yang dilakukan adalah teknik analisis karakteristik peserta didik, teknik analisis tujuan pembelajaran, Teknik analisis pemilihan metode, media dan materi, analisis validitas desain pembelajaran, dan 
338 Pengembangan Desain Pembelajaran Model Assure Berbasis Problem Based Learning Menggunakan Komik di Sekolah Dasar - Neneng Darlis, Farida. F, Yalvema Miaz

DOI: https://doi.org/10.31004/basicedu.v5i1.689

analisis kepraktisan desain pembelajaran serta analisis efektivitas desain pembelajaran.

\section{HASIL DAN PEMBAHASAN}

Tahapan pengembangan desain pembelajaran model ASSURE berbasis PBL telah dilalui dengan hasil produk berupa Rencana Pelaksanaan Pembelajaran (RPP). RPP yang dikembangkan adalah RPP satu lembar sesuai dengan arahan dan edaran Mendikbud RI nomor 14 tahun 2019 tentang penyederhanaan RPP. Proses pengembangan RPP diawali dengan melakukan (a) analisis siswa (analyze learner). Pada tahap ini dilakukan analisis objek berdasarkan hasil dari literatur berupa buku, hasil penelitian, jurnal dan literatur lainnya, (b) merumuskan standar dan tujuan (state standard and objectives). Tujuan pembelajaran adalah rumusan atau pernyataan yang menggambarkanaspek pengetahuan, keterampilan, dan sikap yang diperoleh siswa setelah melalui proses pembelajaran, (c) memilih strategi, teknologi, media dan bahan ajar (select methods, media, andmaterials). Pemilihan metode, media, dan bahan ajar yang tepat dapat mengoptimalkan hasil belajar siswa dalam mencapai kompetensi atau tujuan pembelajaran. (d) menggunakan teknologi, media dan bahan ajar (utilize methods, media, and materials). Hal yang dilakukan pada tahap ini adalah pencermatan umum terhadap teknologi, media, dan materi yang digunakan, penyiapan teknologi, media, dan materi yang digunakan, (e) mengajak partisipasi siswa (requires learner participation). Pada tahap ini siswa dilibatkan dengan cara pemberian contoh, media video, dan latihan yang melibatkan aktifitas mental siswa dengan materi yang sedang dipelajari, (f) evaluasi dan revisi (evaluate and revise). Evaluasi yang dilakukan adalah evaluasi formatif dan sumatif.

Keberhasilan mengembangkan desain pembelajaran model ASSURE pada tematik terpadu dengan kategori sangat baik karena diawali beberapa tahap desain yang sangat kompleks. Secara teoretik, keberhasilan dalam mengembangkan model desain pembelajaran ini sejalan dengan pandangan Hosnan (2014), yang menyatakan bahwa jaring tema sebaiknya disesuaikan dengan kebutuhan peserta didik agar pembelajaran bermakna bagi mereka.

Validasi isi/konten desain pembelajaran dilakukan untuk mengetahui tingkat validitas desain pembelajaran. Hasil validasi pakar berupa koreksi, kritik, dan saran digunakan sebagai dasar untuk merevisi dan menyempurnakan desain pembelajaran yang telah dirancang. Instrumen yang disusun adalah berupa lembar validasi RPP, lembar pengamatan keterlaksanaan RPP, angket respon siswa, angket respon pendidik, dan lembar observasi aktifitas belajar.

Kepraktisan produk diukur dari keterlaksanaan RPP dalam proses pembelajaran yang dilakukan. Data mengenai kepraktisan produk, diperoleh dari hasil pengamatan keterlaksanaan RPP, angket respon siswa terhadap RPP dan angket respon pendidik.

Hasil validasi, koreksi dan saran perbaikan yang diberikan validator digunakan untuk merevisi RPP. Setelah direvisi, RPP divalidasi kembali 
339 Pengembangan Desain Pembelajaran Model Assure Berbasis Problem Based Learning Menggunakan Komik di Sekolah Dasar - Neneng Darlis, Farida. F, Yalvema Miaz

DOI: https://doi.org/10.31004/basicedu.v5i1.689

dengan menggunakan lembar uji validasi. Ini dapat dilihat pada tabel 1 berikut:

Tabel 1. Hasil validasi, koreksi dan saran perbaikan

\begin{tabular}{|c|c|c|}
\hline Validator & Saran Revisi & Revisi yang dilakukan \\
\hline Isi & $\begin{array}{l}\text { 1. Mengambil materi pembelajaran } \\
\text { dari internet, sebaiknya lakukan } \\
\text { ketik ulang, kalau copi scan } \\
\text { tulisan yang digunakan akan } \\
\text { berbeda dengan ketikan sendiri. } \\
\text { 2. Membuat rubrik penilaian sikap } \\
\text { dan keterampilan juga tidak perlu } \\
\text { copy scan dari buku, karena } \\
\text { warna terlihat mencolok. } \\
\text { 3. Sebaiknya komik yang digunakan } \\
\text { sebagai contoh, discan warna dan } \\
\text { dilaminating agar awet dan } \\
\text { terlihat lebih rapi }\end{array}$ & $\begin{array}{l}\text { 2. Dibuat dalam bentuk tabel yang } \\
\text { ditulis sendiri yang tidak } \\
\text { menggunakan warna-warna } \\
\text { mencolok. } \\
\text { 3. Komik sudah discan warna dan } \\
\text { dilaminating }\end{array}$ \\
\hline
\end{tabular}

Aspek penilaian RPP meliputi identitas, rumusan tujuan pembelajaran, langkah-langkah pembelajaran dengan menggunakan model PBL dan penilaian. Berdasarkan rata-rata hasil validasi dari validator tentang RPP maka diperoleh kategori hasil validasi sangat valid berada pada 175 persentase 87,5\% dengan konversi A dengan nilai $85,01 \%$ - $100 \%$. Dengan demikian berarti RPP dapat digunakan sebagai panduan pelaksanaan proses pembelajaran. Dapat dilihat pada tabel 2 berikut:

Tabel 2. Hasil Validasi RPP oleh Validator Ahli

\begin{tabular}{|c|c|c|c|}
\hline \multirow{2}{*}{$\begin{array}{c}\text { Pertemuan } \\
\text { Validator }\end{array}$} & Nilai Validasi & \multirow{2}{*}{ Persentase } & \multirow{2}{*}{ Keterangan } \\
\cline { 2 - 3 } & Kelayakan Isi & & \multirow{2}{*}{ Sangat valid } \\
\hline P1 & 14 & 75 & \\
\hline P2 & 20 & 100 & \\
\hline \multicolumn{2}{|c|}{ Jumlah } & 175 & \\
\hline \multicolumn{2}{|c|}{ Persentase } & 87,5 & \\
\hline
\end{tabular}

Praktikalitas RPP diketahui melalui

keterlaksanaan RPP, angket respon guru, serta angket respon siswa. Keterlaksanaan RPP ditinjau melalui penilaian kegiatan pendahuluan, kegiatan inti, dan penutup dengan rata-rata 3,87 dengan rata-rata persentase $97,08 \%$. Dapat disimpulkan keterlaksanaan RPP secara keseluruhan sangat praktis. Ini dapat dilihat pada tabel 3 berikut:

Tabel 3. Hasil Uji Keterlaksanaan RPP pada Tema 8 kelas V SD

\begin{tabular}{|l|l|c|c|}
\hline No & \multicolumn{1}{|c|}{ Aspek penilaian } & $\begin{array}{c}\text { Rata-rata } \\
\text { validitas }\end{array}$ & Kategori \\
\hline 1. & Pendahuluan & 3,9 & Sangat praktis \\
\hline 2. & Kegiatan inti & 3,85 & Sangat praktis \\
\hline 3. & Penutup & 3,9 & Sangat praktis \\
\hline \multicolumn{2}{|l}{ Rata-rata } & 3,88 \\
\hline
\end{tabular}

Pribadi (2017) menyatakan bahwa peserta didik yang aktif dalam menempuh proses belajar berusaha untuk menemukan informasi dan pengetahuan yang bermakna. Sebaliknya, peserta didik yang pasif dalam proses belajar tidak akan memiliki rasa ingin tahu yang kuat untuk menggali ilmu pengetahuan dan keterampilan yang dipelajari.

Angket respon guru diberikan untuk mengetahui pendapat guru terhadap RPP yang dikembangkan. Angket diisi oleh dua orang guru kelas. Dari hasil analisis data diperoleh respon guru terhadap RPP yang telah dikembangkan memiliki tingkat kepraktisan dalam kategori praktis, rata-rata 3,67 dengan presentase $91,67 \%$. Dan dapat disimpulkan bahwa RPP yang dikembangkan dapat membantu guru dalam pembelajaran. Dapat dilihat pada tabel 4 berikut:

Tabel 4. Angket respon guru

\begin{tabular}{|l|l|c|l|}
\hline No & Aspek penilaian & $\begin{array}{l}\text { Rata-rata } \\
\text { validitas }\end{array}$ & Kategori \\
\hline 1. & $\begin{array}{l}\text { Kepraktisan } \\
\text { Penyajian }\end{array}$ & 4 & Sangat praktis \\
\hline 2. & $\begin{array}{l}\text { Kepraktisan } \\
\text { Penggunaan }\end{array}$ & 4 & Sangat praktis \\
\hline 3. & Waktu & 3 & Sangat praktis \\
\hline Rata-rata & 3,67 & Sangat praktis \\
\hline \multicolumn{2}{|l|}{ Presentase } & $91,67 \%$ & \\
\hline
\end{tabular}


340 Pengembangan Desain Pembelajaran Model Assure Berbasis Problem Based Learning Menggunakan Komik di Sekolah Dasar - Neneng Darlis, Farida. F, Yalvema Miaz

DOI: https://doi.org/10.31004/basicedu.v5i1.689

Angket respon siswa diberikan kepada seluruh siswa kelas V sebagai subjek penelitian. Adapun hasil respon siswa berada pada kategori sangat baik dengan rata-rata persentase $86,16 \%$. Dapat dilihat pada tabel 5 berikut ini:

Tabel 5. Angket respon siswa

\begin{tabular}{|c|c|c|}
\hline No pernyataan & Jumlah & Rata-rata \\
\hline 1 & 102 & 3,4 \\
\hline 2 & 105 & 3,5 \\
\hline 3 & 105 & 3,5 \\
\hline 4 & 99 & 3,3 \\
\hline 5 & 105 & 3,5 \\
\hline 6 & 105 & 3,5 \\
\hline 7 & 99 & 3,3 \\
\hline 8 & 105 & 3,5 \\
\hline 9 & 102 & 3,4 \\
\hline 10 & 102 & 3,4 \\
\hline 11 & 111 & 3,7 \\
\hline Jumlah & 1140 & 38,00 \\
\hline Rata-rata & 103,64 & 3,45 \\
\hline Persentase & \multicolumn{2}{|c}{} \\
\hline
\end{tabular}

Tes hasil belajar siswa dengan penggunaan desain pembelajaran model ASSURE berbasis PBL di kelas V Sekolah Dasar telah mencapai KKM dengan nilai rata-rata 85,71 berdasarkan KKM yang telah ditetapkan di UPTD SDN 02 Simpang Kapuak yaitu 76, dari 28 siswa telah mencapai KKM sebanyak 25siswa, yang artinya pembelajaran sudah efektif digunakan.

Keberhasilan mengembangkan desain pembelajaran model ASSURE pada tematik terpadu dengan kategori sangat baik karena diawali beberapa tahap desain yang sangat kompleks. Secara teoretik, keberhasilan dalam mengembangkan model desain pembelajaran ini sejalan dengan pandangan Hosnan, (2014), yang menyatakan bahwa jaring tema sebaiknya disesuaikan dengan kebutuhan peserta didik agar pembelajaran bermakna bagi mereka.

Temuan bahwa pengembangan desain pembelajaran dengan model ASSURE sejalan dengan penelitian Muhammad Nawawi \& Ana Christanti, (2020) yang meneliti tentang Mendesain Pembelajaran Efektif Berdasarkan Model ASSURE, menunjukan bahwa model mampu menggunakan teknologi terbaru dan media berbasis teknologi ke dalam pembelajaran secara tepat dan efektif. Demikian juga penelitian Kadir, (2018) yang meneliti tentang Peningkatan Kreatifitas Guru dalam Mengajar Melalui pelatihan Model ASSURE dengan Pendekatan Saintifik pada MGMP Pendidikan Agama Islam di Sekolah Menengah Atas Kabupaten Indragiri Hulu Tahun 2017, hasilnya menunjukkan bahwa terjadi peningkatan kemampuan guru setelah diberi pelatihan model ASSURE dari rata-rata kemampuan $44,44 \%$ naik menjadi $100 \%$. Simpulannya, hasil tersebut membuktikan bahwa desain pembelajaran model ASSURE telah valid dan layak digunakan dalam pembelajaran.

Penelitian lain yang sejalan dengan temuan ini adalah penelitian Andriani \& Wahyudi, (2016) meneliti tentang Pengembangan Media Pembelajaran Power Point Interaktif Melalui Pendekatan Saintifik Untuk Pembelajaran Tematik Integratif Siswa Kelas 2 SDN Bergas Kidul 03 Kabupaten Semarang.

Berdasarkan hasil uji efektivitas diperoleh bahwa aktivitas positif menunjukkan persentase yang cenderung meningkat untuk setiap pertemuan. Pribadi, (2017) menyatakan bahwa peserta didik yang aktif dalam menempuh proses belajar berusaha untuk menemukan informasi dan pengetahuan yang bermakna. Sebaliknya, peserta didik yang pasif dalam proses belajar tidak akan memiliki rasa ingin tahu yang kuat untuk menggali 
341 Pengembangan Desain Pembelajaran Model Assure Berbasis Problem Based Learning Menggunakan Komik di Sekolah Dasar - Neneng Darlis, Farida. F, Yalvema Miaz

DOI: https://doi.org/10.31004/basicedu.v5i1.689

ilmu pengetahuan dan keterampilan yang dipelajari.

Temuan bahwa efektivitas desain pembelajaran dengan model ASSURE ini sejalan dengan temuan Utami et al., (2018) meneliti tentang Pengaruh Penggunaan Model ASSURE Terhadap Peningkatan Prestasi Belajar IPA Tunalaras Kelas IV di SLB E Bhina Putera Surakarta Tahun Ajaran 2017/2018 menunjukkan Model ASSURE dapat meningkatkan prestasi belajar pada mata pelajaran IPA materi gaya.

\section{SIMPULAN}

Berdasarkan hasil penelitian dan pembahasan yang telah dilaksanakan, maka dapat diambil beberapa kesimpulan yaitu proses pengembangan desain pembelajaran menggunakan model ASSURE dikembangkan berdasarkan analisis tahap-tahap model ASSURE. Validitas hasil model desain pembelajaran model ASSURE tematik terpadu berada pada kategori sangat valid. Praktikalitas hasil model desain pembelajaran model ASSURE tematik terpadu dapat terlaksana dengan baik pada pembelajaran di dalam kelas. Dan efektivitas hasil model desain pembelajaran model ASSURE tematik terpadu berpengaruh terhadap keterlaksanaan RPP, aktivitas dan hasil belajar peserta didik.

\section{DAFTAR PUSTAKA}

Andriani, M. R., \& Wahyudi. (2016). Pengembangan Media Pembelajaran Power Point Interaktif Melalui Pendekatan Saintifik Untuk Pembelajaran Tematik Integratif Siswa Kelas 2 Sdn Bergas Kidul 03 Kabupaten Semarang. Scholaria: Jurnal Pendidikan Dan Kebudayaan. https://doi.org/10.24246/j.scholaria.2016.v6.i 1.p143-157

Arigiyati, T. A. (2016). Implementasi Penilaian Autentik Untuk Meningkatkan Hasil Belajar Matematika Siswa. Jurnal Pendidikan Progresif.

Baharun, H. (2016). Pengembangan Media Pembelajaran Pai Berbasis Lingkungan Melalui Model ASSURE. Cendekia: Journal of Education and Society. https://doi.org/10.21154/cendekia.v14i2.610

Bajracharya, J. R. (2019). Instructional Design and Models: ASSURE and Kemp. Journal of Education and Research. https://doi.org/10.3126/jer.v9i2.30459

Charlina, U., Anggraini, R., \& Herawati, S. (2020). Buku Komik Lokal Sebagai Media Pengenalan Kearifan Lokal Sumatera Selatan (Lahat) Pada Anak Sekolah Dasar. Kalpataru: Jurnal Sejarah Dan Pembelajaran Sejarah. https://doi.org/10.31851/kalpataru.v5i2.4115

Daryanto, \& Tasrial. (2012). Konsep pembelajaran kreatif. Psikologi Pendidikan.

Hosnan. (2014). Pendekatan Saintifik dan Kontekstual dalam Pembelajaran Abad 21. Ghalia Indonesia.

Kadir, A. (2018). Peningkatan Kreativitas Guru Dalam Mengajar Melalui Pelatihan Model Assure Dengan Pendekatan Scientific Pada Mgmp Pendidikan Agama Islam Di Sekolah Menengah Atas Kabupaten Indragiri Hulu Tahun 2017. Akademika.

Kemendikbud. (2016). Standar Proses Pendidikan Dasar dan Menengah. Lampiran Permendikbud.

Krissandi, A. D. S., \& Rusmawan, R. (2015). Kendala Guru Sekolah Dasar Dalam Implementasi Kurikulum 2013. Jurnal Cakrawala Pendidikan. https://doi.org/10.21831/cp.v3i3.7409

Kusnandar. (2013). Penilaian autentik (Penilaian Hasil Belajar Peserta Didik berdasarkan Kurikulum 2013. Raja Grasindo Persada.

Muhammad Nawawi, \& Ana Christanti. (2020). Promotıng Multiliteracy Framework - Based Lesson Plan for Englısh Language Teaching 
342 Pengembangan Desain Pembelajaran Model Assure Berbasis Problem Based Learning Menggunakan Komik di Sekolah Dasar - Neneng Darlis, Farida. F, Yalvema Miaz

DOI: https://doi.org/10.31004/basicedu.v5i1.689

In Senior High School. Education and Human Development Journal. https://doi.org/10.33086/ehdj.v5i2.1549

Pribadi, R. B. A. (2017). Media dan Teknologi dalam Pembelajaran. Jakarta: Kencana.

Puspitorini, R., Prodjosantoso, A. K., Subali, B., \& Jumadi, J. (2014). Penggunaan Media Komik Dalam Pembelajaran Ipa Untuk Meningkatkan Motivasi Dan Hasil Belajar Kognitif Dan Afektif. Jurnal Cakrawala Pendidikan.

https://doi.org/10.21831/cp.v3i3.2385

Sagala, S. (2012). Konsep dan Makna Pembelajaran: Untuk Membantu Memecahkan Problematika Belajar dan Mengajar. In Bandung: Alfabeta.

Utami, D. W., Anwar, M., \& Hermawan, H. (2018). Pengaruh Penggunaan Model Pembelajaran Assure Terhadap Peningkatan Prestasi Belajar IPA Anak Tunalaras Kelas IV Di SLB E Bhina Putera Surakarta Tahun AjaraN 2017/2018. JPI (Jurnal Pendidikan Inklusi).

https://doi.org/10.26740/inklusi.v2n1.p5-14 